\title{
EXTENSÃo E PESQUisa NA ÁREA DA SAÚdE: UMA INTERLOCUÇÃo SOCIALMENTE CONSTRUÍDA
}

\author{
Murilo Lyra Pinto ${ }^{1}$ \\ Marcos Rodrigo Rita ${ }^{2}$ \\ Nerilaine Lasch $^{3}$ \\ Rafael Thiago Laurentino ${ }^{4}$ \\ Tirza Oliveira $\mathrm{Cruz}^{5}$ \\ David Rivero Tames ${ }^{6}$ \\ Marco Aurelio da Ros ${ }^{7}$ \\ Rita de Cássia Gabrielli Souza Lima ${ }^{8}$
}

Resumo: Apresenta uma revisão bibliográfica sobre extensão universitária, realizada no Portal Regional BVS por integrantes do Projeto de Extensão Antonio Gramsci: fomentando a concepção ativista de educação, da Universidade do Vale do Itajaí, SC. Os objetivos foram aproximar extensão e pesquisa, identificando se a dimensão histórica e a dimensão reflexivo-crítica foram exploradas em produções científicas sobre extensão, a partir dos anos 90, marco da regulamentação legal do Sistema Único de Saúde (SUS), até 2014. Na relação com os vinte e dois artigos que compuseram o universo de estudo, apreendeuse que algumas produções científicas utilizaram a dimensão histórica e a reflexivo-crítica em descrições e/ou narrativas. O estudo reafirmou que a extensão é uma modalidade formativa basilar para a formação para o SUS, por despertar os acadêmicos para a realidade, fora dos muros, e que o diálogo entre extensão e pesquisa amplia os horizontes humanos.

Palavras-chave: Extensão Universitária; Abordagem histórica; Reflexividade; Criticidade; SUS.

\footnotetext{
${ }^{1}$ Curso de Nutrição/Universidade do Vale do Itajaí (UNIVALI), Brasil. E-mail: mu.lyra@gmail.com.

${ }^{2}$ Curso de Odontologia/UNIVALI, Brasil. E-mail: marcosritasjb@hotmail.com.

${ }^{3}$ Curso de Odontologia/UNIVALI, Brasil. E-mail: neri_lasch@hotmail.com.

${ }^{4}$ Curso de Odontologia/UNIVALI, Brasil. E-mail: rafaelthiagol@hotmail.com.

${ }^{5}$ Curso de Odontologia/UNIVALI, Brasil. E-mail: tirzinha_164@hotmail.com.

${ }^{6}$ Curso de Odontologia/UNIVALI, Brasil. E-mail: dtames@univali.br.

${ }^{7}$ Curso de Medicina/UNIVALI, Brasil. E-mail: ros@univali.br.

${ }^{8}$ Curso de Odontologia/UNIVALI, Brasil. E-mail: rita.lima@univali.br.
} 